\title{
Originalien
}

Notfall Rettungsmed 2021 · 24 (Suppl 1):S32-S38 https://doi.org/10.1007/s10049-021-00860-6 Accepted: 4 March 2021

Published online: 25 March 2021

(c) Springer Medizin Verlag GmbH, ein Teil von Springer Nature 2021
Asim Enes Ozbek ${ }^{1,2}$ (D) Emre Sanci ${ }^{1}$ (D) $\cdot$ Huseyin Cahit Halhalli ${ }^{1}$ (D)

'Department of Emergency Medicine, University of Health Sciences Kocaeli Derince Training and Research Hospital, Kocaeli, Turkey

${ }^{2}$ University of Health Sciences Kocaeli Derince Training and Research Hospital, Derince, Kocaeli, Turkey

\section{Effect of using barrier devices on intubation times and performance-a randomized, prospective, crossover manikin study}

\section{Introduction}

Severe acute respiratory syndrome coronavirus 2 (SARS-CoV-2) is transmitted by exposure to infected secretions, and the transmission risk is higher for healthcare professionals $[5,6]$. The Chinese Centre for Disease Control and Prevention reported that $3.8 \%$ of cases were healthcare professionals, among which emergency medicine staff constitutes almost one fifth $[27,30]$. In addition, emergency medicine physicians and general practitioners comprise $42 \%$ of physician deaths [11].

Although approximately $80 \%$ of COVID-19 cases are mild, $8-10 \%$ of patients require endotracheal intubation. Endotracheal intubation is a highrisk, aerosol-generating procedure that increases the risk of transmission [10, 33]. Furthermore, the high viral load in the sputum and upper airway secretions of patients and the high concentrations of respiratory aerosols during endotracheal intubation pose a great risk for transmission to emergency medicine physicians [31]. This risk increases with the endotracheal intubation operators' proximity to the patient's airway; therefore, using auxiliary devices such as a video laryngoscope, an aerosol box, or a plastic drape have been emphasized for airway management in this unprecedented pandemic period [26, 28].
The patient's position during endotracheal intubation may affect the first-pass success rate and intubation time [29]. Two commonly accepted patient positions during endotracheal intubation are the sniffing position and the ramped position [24]. Since the optimal airway management position in critically ill patients during endotracheal intubation remains controversial, the position that is most useful to improving first-pass success rates and intubation times should be investigated [12, 24, 32].

To decrease the transmission risk, airway management guidelines recommend that physicians wear personal protective equipment (PPE) during aerosol-generating procedures, including endotracheal intubation [3, 7, 15]. Additionally, the aerosol box was invented to make endotracheal intubation safer [14]. It was reported that droplet spread decreased with the use of an aerosol box [4]. Furthermore, a transparent plastic drape was also designed to decrease the spread of droplets during endotracheal intubation $[9,20]$.

The incidence of three or more intubation attempts in critical care patients ranged from 8 to $20 \%$ [21]. Multiple intubation attempts increased both the SARSCoV-2 transmission rates to physicians and the complication rates for patients [17]. Therefore, it is important to identify the method that does not decrease the likelihood of first-pass success rates without increasing intubation times.

The aim of this study is to compare the use of conventional PPE, aerosol box, and transparent plastic drape and their impact on intubation times during endotracheal intubation by experienced emergency medicine specialists on a manikin both in the ramped and sniffing positions.

\section{Methods}

\section{Study design and settings}

This randomized, prospective, crossover manikin simulation study was conducted in July 2020 at a tertiary academic care center. The study was approved by the local ethics committee (2020/56). Written informed consent was obtained from all participants included in the study.

Thirteen emergency medicine specialists from one university who had at least 5 years of clinical experience in airway management participated in the study. However, the participants had no prior plastic drape (PD) or aerosol box $(A B)$ experience when this study was conducted. The participants were aware of the general nature of the study but were blinded to its specific objectives. Each participant was offered an opportunity to practice each method once on the manikin (Life/form ${ }^{\circledR}$ Deluxe Crisis $^{\mathrm{Tm}}$ Manikin Torso with advanced airway management). Tracheal tubes 

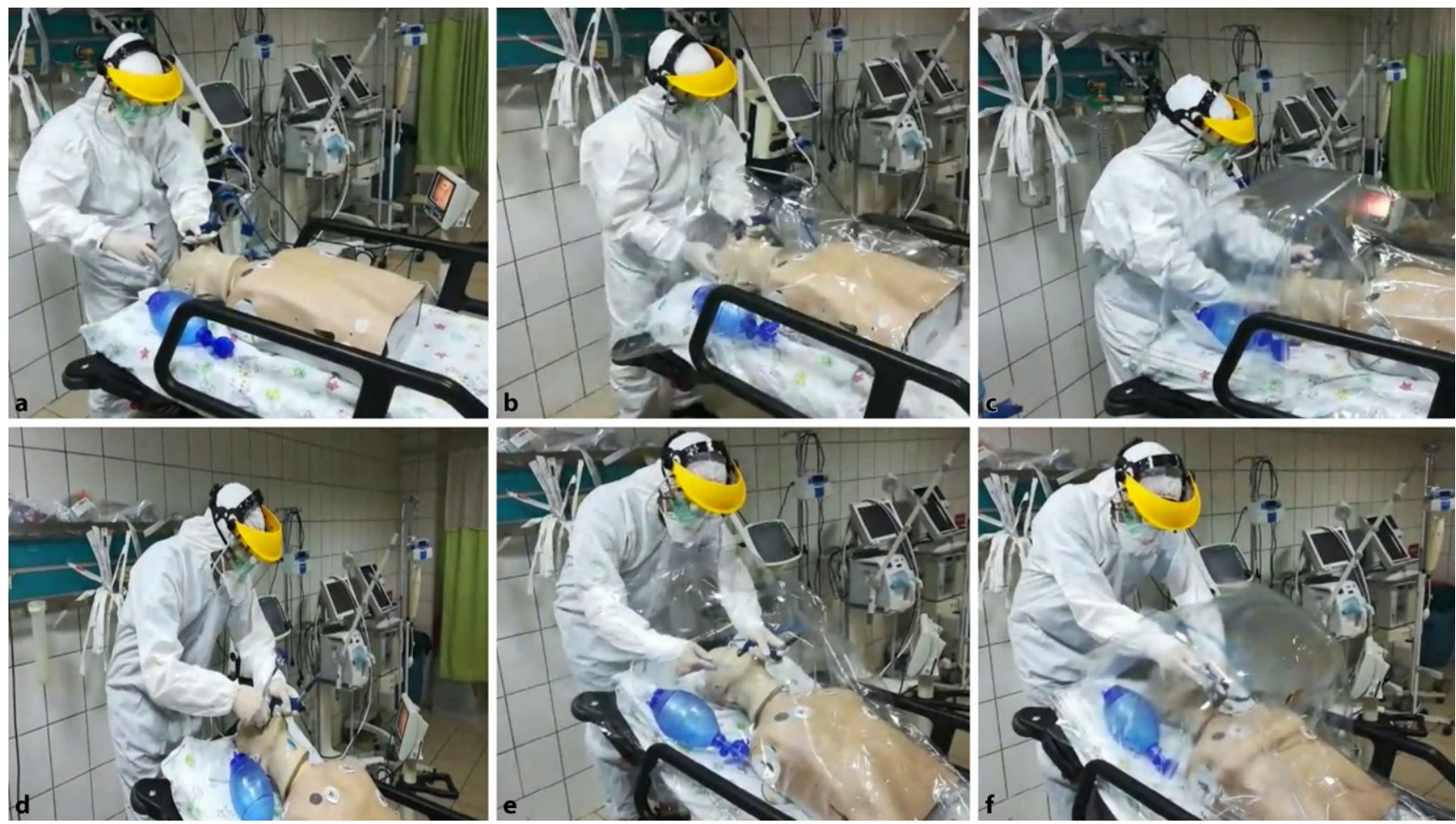

Fig. $1 \Delta$ Use of the barrier devices and personal protective equipment (PPE) in sniffing and ramped positions. a PPE; sniffing position. $\mathbf{b}$ Transparent plastic drape; sniffing position. c Aerosol box; sniffing position. $d$ PPE; ramped position. e Transparent plastic drape; ramped position. $f$ Aerosol box; ramped position

with an internal diameter of $8 \mathrm{~mm}$ and Glidescope $^{\circledast}$ (GVL; Verathon Medical Inc., Bothell, WA, USA) with a reusable blade $\left(\mathrm{GVL}^{\circledR}\right.$ - 115; Verathon Medical Inc., Bothell, WA, USA) were used for the endotracheal intubations. The manikin was placed on a stretcher. The equipment needed for each intervention was placed beside the head of the manikin.

A local supplier designed and provided the second generation aerosol box which is larger than first generation aerosol boxes with dimension of $50 \mathrm{~cm}$ in height, $50 \mathrm{~cm}$ in width, and $40 \mathrm{~cm}$ in length. Since the $10-\mathrm{cm}$ arm holes of the early-generation aerosol box limited the maneuverability of the operators, the width of the armholes in our modified aerosol box was increased to $15 \mathrm{~cm}$ [14]. A transparent, plastic drape $200 \mathrm{~cm}$ long by $140 \mathrm{~cm}$ wide and $1 \mathrm{~mm}$ thick was placed over the manikin for the plastic drape scenarios, and the transparent drape was also placed over the aerosol box during the aerosol box scenarios. In the $30^{\circ}$ ramped position, the head of the bed was elevated until the external acoustic meatus and the sternal notch of the manikin were horizontally aligned. The $30^{\circ}$ elevation was adjusted using the Bubble Level application in an android version 8.0.0 mobile device. In accordance with airway management guidelines, all of the operators wore personal protective equipment (PPE) including a long-sleeved gown, an FFP3 mask, goggles, headwear, a face-shield, and gloves [7, 15].

Operators intubated the manikin using the following protection methods: (1) conventional PPE, (2) an aerosol box as an adjunct to PPE, and (3) a transparent plastic drape as an adjunct to PPE in each of two scenarios: in scenario (a), the manikin was placed in the sniffing position, and in scenario (b), the manikin was placed in the $30^{\circ}$ ramped position. Therefore, each participant performed six airway interventions (• Fig. 1).

To lessen the learning effects, a randomized, crossover study design was used. The order of the interventions was randomized for each participant by an online program (www.randomization. com) that yielded a total of six endotracheal intubations per participant.
Participants were requested to finish each intervention within two minutes [18]. For each method, participants were allowed one attempt to successfully intubate the manikin. The duration of the endotracheal intubation attempt was defined as the time elapsed between insertion and removal of the laryngoscope from the manikin's mouth [8]. Each procedure was recorded by video camera. After the interventions, for each method, the participants were asked to grade the difficulty of accessing the equipment, inserting the endotracheal tube into the glottis, maneuvering of the laryngoscope, and gaining a clear view of the manikin's face on a 5-point Likert scale: $1=$ "very easy," 2 = "easy," 3 = "moderate," $4=$ "difficult," and $5=$ "very difficult."

\section{Outcome measures}

The primary outcome of the study was a comparison of the endotracheal intubation times for each method. The secondary outcomes were the first-pass success rates and the difficulty levels of accessing the equipment, inserting the 
Notfall Rettungsmed 2021 - 24 (Suppl 1):S32-S38 https://doi.org/10.1007/s10049-021-00860-6

(c) Springer Medizin Verlag GmbH, ein Teil von Springer Nature 2021

\section{A. E. Ozbek · E. Sanci · H. C. Halhalli}

\section{Effect of using barrier devices on intubation times and performance-a randomized, prospective, crossover manikin study}

Abstract

Background. The impact of barrier devices on endotracheal intubation times is unknown. Objective. We sought to compare the effects using conventional personal protective equipment, an aerosol box, and a transparent plastic drape on intubation times by experienced emergency physicians on a manikin in both the sniffing and ramped positions in a randomized, prospective crossover study design.

Methods. A total of 13 experienced emergency physicians performed endotracheal intubations on a manikin in both the sniffing and ramped positions using conventional personal protective equipment (PPE), an aerosol box, and a transparent plastic drape.
The primary outcome was intubation time; secondary outcomes included first-pass success rates and ratings of difficulty in accessing the device, inserting the endotracheal tube into the glottis, maneuvering the laryngoscope, and clear vision of the manikin's face. Results. The use of an aerosol box or transparent plastic drape increased intubation times in both the sniffing and ramped positions. First-pass success rates did not differ between the groups. Perceptions of difficulty accessing the device, inserting the endotracheal tube into the glottis, maneuvering the laryngoscope, and obtaining a clear view of the manikin's face to the model were higher when using the aerosol box and transparent plastic drape compared to intubation with only PPE.

Conclusion. An aerosol box and transparent plastic drape may increase intubation times during endotracheal intubation of coronavirus disease 2019 (COVID-19) patients in both the sniffing and ramped positions. Further research should investigate the utility of these devices during endotracheal intubation. Trial registration number and date: NCT04412226; 31 May 2020.

Keywords

Aerosol box · Barrier device · COVID-19 - Airway management $\cdot$ Personal protective equipment

\section{Auswirkungen der Verwendung von Barrieregeräten auf die Intubationszeiten und -leistung - eine randomisierte, prospektive Cross-over-Modellstudie}

\section{Zusammenfassung}

Hintergrund. Der Einfluss von Barrieregeräten auf die endotrachealen Intubationszeiten ist nicht bekannt.

Zielsetzung. In einer randomisierten, prospektiven Cross-over-Studie wurden die Auswirkungen der Verwendung herkömmlicher persönlicher Schutzausrüstung, einer Aerosolbox und eines transparenten Kunststofftuchs auf die Intubationszeiten verglichen, wenn erfahrene Notfallmediziner an einem Modell sowohl in der Schnüffel- als auch in der Rampenposition arbeiteten.

Methoden. Dreizehn erfahrene Notfallmediziner führten endotracheale Intubationen an einem Modell in der Schnüffel- und Rampenposition mit herkömmlicher persönlicher Schutzausrüstung, einer Aerosolbox und einem transparenten Kunststofftuch durch. Der primäre Endpunkt war die Intubationszeit.
Zu den sekundären Endpunkten zählten die Erfolgsraten beim ersten Durchgang und die Bewertung des Schwierigkeitsgrads beim Zugriff auf das Gerät, Einführen des Endotrachealtubus in die Glottis, Manövrieren des Laryngoskops und Erreichen einer klaren Sicht auf das Gesicht des Modells.

Ergebnisse. Die Verwendung einer Aerosolbox oder eines transparenten Kunststofftuchs verlängerte die Intubationszeiten sowohl in der Schnüffel- als auch in der Rampenposition. Die Erfolgsraten beim ersten Versuch unterschieden sich nicht zwischen den Gruppen. Die Wahrnehmung der Schwierigkeit, auf das Gerät zuzugreifen, den Endotrachealtubus in die Glottis einzuführen, das Laryngoskop zu manövrieren und eine klare Sicht auf das Gesicht des Modells zu erreichen, war bei Verwendung der Aerosolbox und des transparenten Plastiktuchs höher. Schlussfolgerung. Eine Aerosolbox und ein transparentes Kunststofftuch können die Intubationszeiten während der endotrachealen Intubation von Patienten mit "coronavirus disease 2019" (COVID-19) sowohl in der Schnüffel- als auch in der Rampenposition verlängern. Der Nutzen dieser Geräte während der endotrachealen Intubation sollte in weiteren Forschungsarbeiten untersucht werden.

Studienregistrierungsnummer und -datum: NCT04412226; 31.05.2020

Schlüsselwörter

Aerosolbox · Absperrvorrichtung · COVID19. Atemwegsmanagement - Persönliche Schutzausrüstung endotracheal tube into the glottis, maneuvering the laryngoscope, and gaining a clear view of the manikin's face.

\section{Primary data analysis}

Statistical analyses were performed using SPSS version 22 (SPSS, Inc., Chicago, IL, USA). The normality of the distribution of data was examined by the Kolmogorov-Smirnov/Shapiro-Wilk tests.
Descriptive statistics are presented as the mean and standard deviation for parametric variables and the median and interquartile range for nonparametric variables. The data showing a normal distribution were compared using a paired $t$ test, and the data lacking a normal distribution were compared using the Mann-Whitney U test. Categorical variables in independent groups were analyzed with the $\mathrm{X}^{2}$ test. $\mathrm{P}$ values less than 0.05 were considered statistically significant. To calculate sample size, the means of intubation times were used in the study by Begley et al. exploring aerosol box utilization for intubation in coronavirus disease. Based on their findings, using a confidence interval of 0.05 and power $=80 \%$, the present study aimed to recruit 13 patients in each group. The sample size for the 
Table 1 Time to intubation for each simulated scenario (seconds)

\begin{tabular}{|c|c|c|c|c|}
\hline & $\begin{array}{l}\text { PPE }^{\mathrm{a}} \\
(n=13)\end{array}$ & $\begin{array}{l}\text { Plastic drape }^{a} \\
(n=13)\end{array}$ & $\begin{array}{l}\text { Aerosol box }{ }^{a} \\
(n=13)\end{array}$ & $p$ value \\
\hline $30^{\circ}$ Elevated scenario & $13.5 \pm 6.2$ & $21.2 \pm 13.6$ & $17.5 \pm 11.9$ & 0.219 \\
\hline Supine scenario & $12.8 \pm 6$ & $14.5 \pm 6.2$ & $15.9 \pm 8$ & 0.656 \\
\hline$p$ value & 0.687 & 0.267 & 0.935 & - \\
\hline
\end{tabular}

Table 2 Likert scale results of the self-perceived difficulty level of acquiring clarity, maneuverability of the laryngoscope, inserting the endotracheal tube into the glottis and accessing the equipment, with use of the AB, PD and PPEboth in sniffing and ramped positions

\begin{tabular}{|c|c|c|c|}
\hline $\begin{array}{l}\text { Sniffing posi- } \\
\text { tion }\end{array}$ & $\begin{array}{l}\text { Very easy, easy } \\
\text { (\%) }\end{array}$ & $\begin{array}{l}\text { Moderate } \\
\text { (\%) }\end{array}$ & $\begin{array}{l}\mathrm{Di} \\
(\%\end{array}$ \\
\hline \multicolumn{4}{|l|}{ Acquiring clarity } \\
\hline PPE & 100 & 0 & 0 \\
\hline PD & 38 & 38 & 23 \\
\hline$A B$ & $23 \%$ & 69 & 8 \\
\hline \multicolumn{4}{|l|}{ Maneuverability } \\
\hline PPE & 85 & 8 & 8 \\
\hline PD & 31 & 38 & 31 \\
\hline$A B$ & 15 & 31 & 54 \\
\hline
\end{tabular}

Difficulty of inserting

PPE $\quad 92$

PD $\quad 46$

$\mathrm{AB} \quad 31$

Accessing

PPE

$P D$

$A B$

Ramped posi-

tion

Acquiring clarity

\begin{tabular}{|l|l|}
\hline PPE & 77 \\
\hline PD & 31 \\
\hline AB & 31 \\
\hline Maneuverability & \\
\hline PPE & 100 \\
\hline PD & 31 \\
\hline AB & 15 \\
\hline
\end{tabular}

Difficulty of inserting

PPE $\quad 92$

PD 54

AB 23

Accessing

PPE 100

$P D$

$\mathrm{AB}$

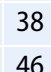

46

$A B$ aerosol box, $P P E$ personal protective equipment, $P D$ plastic drape present study was calculated using www. openepi.com.

\section{Results}

Thirteen emergency specialists participated in the study. In the ramped scenario, the intubation times did not differ significantly between PPE, plastic drape, or aerosol box $(13.5 \pm 6.2,21.2 \pm 13.6$, $17.5 \pm 11.9$, respectively; $p=0.219$ ). In the sniffing scenario, intubation times also did not differ significantly between PPE, plastic drape, or aerosol box $(12.8 \pm 6,14.5 \pm 6.2,15.9 \pm 8$, respectively; $p=0.656)$. When elevated and sniffing scenario intubation times were compared for each method, there were no significant differences between PPE $(13.5 \pm 6.2,12.8 \pm 6, p=0.687)$, plastic drape $(21.2 \pm 13.6,14.5 \pm 6.2, p=0.267)$, or aerosol box $(17.5 \pm 11.9,15.9 \pm 8$, $p=0.935)$, respectively. Intubation times for each method are summarized in - Table 1.

First-pass success rates in the elevated scenario did not differ significantly between PPE, plastic drape, or aerosol box (13/13 [100\%], 13/13 [100\%], 12/13 [92\%], respectively; $p=0.358)$. All participants successfully intubated on their first attempt in the sniffing scenario with PPE, plastic drape, and aerosol box (13/13 [100\%], 13/13 [100\%], 13/13 [100\%], respectively).

The difficulty of accessing the equipment, inserting the endotracheal tube into the glottis, maneuvering the laryngoscope, and gaining a clear view of the manikin's face using the aerosol box, the transparent plastic drape, and conventional PPE were evaluated using a 5point Likert scale. Using PPE, 11 of the 13 physicians (84\%) rated the difficulty of accessing the equipment and inserting the endotracheal tube into the glottis during the sniffing scenario "very easy" and "easy". Using the aerosol box, only 4 of the physicians $(31 \%)$ rated the difficulty of accessing the equipment and inserting the endotracheal tube into the glottis during the sniffing scenario as "very easy" and "easy". Using the plastic drape, 6 of the physicians $(46 \%)$ rated the difficulty of accessing the equipment and inserting the endotracheal tube into the glottis 
during the sniffing scenario as "very easy" and "easy". Likert scale results of participant's self-perceived performances have been summarized in $\bullet$ Table 2 .

\section{Discussion}

Airway management whilst wearing PPE may lead to challenges including, anxiety, suboptimal communication, excess heat, unclear view $[1,25]$. On the other hand, there is a lack of evidence about the effect of PPE usage during airway management [23].

Although several variations of aerosol boxes and transparent plastic drapes have been built recently, it is uncertain how often they have been used in clinical settings $[4,9,16]$. In addition, it is uncertain if they extend intubation time. There is no evidence supporting their use in the emergency department (ED). To the best of our knowledge, this is the first study that compares the impact of these devices on endotracheal intubation times and first-pass success rates in the ED. These devices are physical barriers; therefore, they could introduce difficulties in the intubation parameters that impact both success rates and intubation times. However, our study results showed that there was no statistical association between use of barrier devices and intubation times. The first-pass success rates were also similar between the groups.

Existing data suggest that using an aerosol box results in lower first-pass success rates and longer intubation times [2]. While the intubation times were not significantly different between the groups in our study, intubation times were longer in all groups with the use of the aerosol box and the transparent plastic drape. Although the difference between the means of endotracheal intubation times were less than eight seconds in all groups, in critically ill patients, this prolongation may increase the risk of aspiration and hypoxia [18]. Accessing the equipment, inserting the endotracheal tube into the glottis, and maneuvering the laryngoscope are the main components of the endotracheal intubation procedure that may affect both intubation times and first-pass success rates.
In this study, the participants perceived accessing the equipment, inserting the endotracheal tube into the glottis, and maneuvering the laryngoscope as well as gaining a clear view of the manikin's face as more difficult with the use of an aerosol box and a transparent plastic drape compared with the use of regular PPE alone. The participants' pre-existing intubation experience with conventional PPE might have contributed to the longer intubation times with the aerosol box and the transparent plastic drape.

The results of this study are consistent with previous data that showed that there was no statistical association between the use of the sniffing or ramped position and either intubation times or first-pass success rates $[22,24]$. Although intubation times were not significantly different using the sniffing or ramped position, intubation times were longer in all groups that used the ramped position. In our institution, less use of the ramped position might have contributed to the longer intubation times [5].

In contrast to a manikin study conducted in an intensive care unit, in our study, first-pass success rates were not significantly different between the groups [2]. This discrepancy might be attributable to differences in the study design and the cognitive overload, training, and procedural skills of the operators or any combination of these factors. For instance, although difficult airway was simulated via inflated tongue by Begley et al., difficult airway management scenarios such as blood, vomit, foreign bodies, airway edema, cervical collar were not simulated [2]. Using difficult airway scenarios could have affected the study findings. Furthermore, the wider armholes of the aerosol box in our study might have contributed to the inconsistencies between the two studies.

\section{Limitations}

This study has several limitations. First, it was conducted in a model setting in a single center; therefore, our study results cannot be generalized. Manikin studies cannot simulate conditions encountered in clinical settings such as blood, vomit, sputum, airway edema, or fogging of the device during endotracheal intubation. However, because of the ethical issues, it is common to evaluate the effect of new devices on airway management through simulation studies $[13,18]$. Second, in this study, in accordance with the current guidelines, the endotracheal intubations were performed by experienced physicians. However, especially during the pandemic, due to the shortage of highly qualified staff, endotracheal intubations may be performed by physicians with less experience [19]. The results of the study would likely differ if the intubations had been performed by unseasoned providers. Therefore, the results of the study cannot be generalized to all physicians. Third, most of the participants had pre-existing experience of intubation with conventional PPE. This could have affected the study findings. To overcome this limitation, participants were offered an opportunity to practice each method once on the manikin. Fourth, although the aerosol box and transparent plastic drape were designed to decrease the spread of droplets and aerosols, there is currently no evidence that these barrier devices prevent distribution of small particles. However, this topic is beyond the scope of this study. Fifth, the participants in this study were experienced emergency medicine specialists. Thus, they were not offered training for airway management before the study. In order to make the participants familiar with the barrier devices, they were allowed one attempt to intubate the manikin. This methodology might have affected the results of the study by their effects on intubation times and first-pass success rates, on the other hand familiarization with the methods might demonstrate the actual difference of the intubation times and first-pass success rates. Sixth, airway management is a procedure that includes lots of interventions as preoxygenation, positioning and suctioning. During the COVID19 pandemic since the airway management guidelines recommend full careful donning of PPE before attending to the patient, intubation times extended [7]. When interpreting our results, it should be taken into account that these factors have not been measured in our study. Our study aimed to compare the time 
elapsed between insertion and removal of the laryngoscope for intubation.

\section{Conclusion}

The findings of this study suggest that there was no statistical association between use of barrier devices and intubation times during endotracheal intubation simulation in an emergency department both in the sniffing and ramped positions. In addition, there was no statistical association between use of barrier devices and first-pass success rates during endotracheal intubation simulation in both the sniffing and ramped positions. Furthermore, difficulty with the use of an aerosol box and a transparent plastic drape for accessing the equipment, inserting the endotracheal tube into the glottis, and maneuvering the laryngoscope as well as gaining a clear view of the manikin's face may lead to challenges especially in difficult airway situations. Further randomized controlled studies should investigate the utility of these devices during endotracheal intubation and other aerosol-generating procedures.

\section{Corresponding address}

\section{Asim Enes Ozbek, M.D.}

University of Health Sciences Kocaeli Derince

Training and Research Hospital

41900 Derince, Kocaeli, Turkey

drenesozbek@gmail.com

Funding. This research did not receive any specific grant from funding agencies in the public, commercial, or not-for-profit sectors.

\section{Declarations}

Conflict of interest. A.E. Ozbek, E. Sanci and H.C. Halhalli declare that they have no competing interests.

Approval was obtained from the ethics committee of University of Health Sciences Kocaeli Derince Training and Research Hospital (2020/56). The procedures used in this study adhere to the tenets of the Declaration of Helsinki.

\section{References}

1. Ansari U, Mendonca C, Danha R et al (2020) The effects of personal protective equipment on airway management: an in-situ simulation. Trends Anaesth Crit Care 34:23-27. https://doi.org/10. 1016/j.tacc.2020.07.003
2. Begley JL, Lavery KE, Nickson CP, Brewster DJ(2020) The aerosol box for intubation in coronavirus disease 2019 patients: an in-situ simulation crossover study. Anaesthesia 75:1014-1021. https://doi.org/10.1111/anae.15115

3. Brewster DJ, Chrimes N, Do TB et al (2020) Consensus statement: safe airway society principles of airway management and tracheal intubation specific to the COVID-19 adult patient group. Med J Aust 212:472-481. https://doi.org/ 10.5694/mja2.50598

4. Canelli R, Connor CW, Gonzalez M et al (2020) Barrier enclosure during endotracheal Intubation. N Engl J Med 382:1957-1958. https://doi.org/10. 1056/NEJMc2007589

5. Carlson JN, Zocchi M, Marsh K et al (2019) Procedural experience with intubation: results from a national emergency medicine group. Ann Emerg Med 74:786-794. https://doi.org/10.1016/ j.annemergmed.2019.04.025

6. CDC (2020)Coronavirus disease 2019(COVID-19) in the U.S. https://www.cdc.gov/coronavirus/2019ncov/cases-updates/cases-in-us.html. Accessed 11 Aug 2020

7. Cook TM, El-Boghdadly K, McGuire B et al (2020) Consensus guidelines for managing the airway in patients with COVID-19: guidelines from the difficult airway society, the association of Anaesthetists the intensive care society, the faculty of intensive care medicine and the royal college of anaesthetists. Anaesthesia 75:785-799. https:// doi.org/10.1111/anae.15054

8. Driver BE, Prekker ME, Klein LR et al (2018) Effect of use of a Bougie vs endotracheal tube and stylet on first-attempt Intubation success among patients with difficult airways undergoing emergency Intubation: a randomized clinical trial. JAMA 319:2179. https://doi.org/10.1001/jama.2018. 6496

9. Emami N, TannerT, Ogundipe Fetal (2020) Drape to prevent disease transmission during endotracheal intubation. Am J Infect Control. https://doi.org/10. 1016/j.ajic.2020.06.212

10. Grasselli G, Zangrillo A, Zanella A et al (2020) Baseline characteristics and outcomes of 1591 patients infected with SARS-coV-2 admitted to ICus of the Lombardy region, Italy. JAMA 323:1574-1581. https://doi.org/10.1001/jama. 2020.5394

11. Ing EB, Xu QA, Salimi A, Torun N (2020) Physician deaths from corona virus (COVID-19) disease. Occup Med 70:370-374. https://doi.org/10.1093/ occmed/kqaa088

12. Khandelwal N, Khorsand S, Mitchell SH, Joffe AM (2016) Head-elevated patient positioning decreases complications of emergent tracheal intubation in the ward and intensive care unit. Anesth Analg 122:1101-1107. https://doi.org/10. 1213/ANE.0000000000001184

13. Kovacs G, Law JA, McCrossin C et al (2007) A comparison of a fiberoptic stylet and a Bougie as adjuncts to direct laryngoscopy in a manikin-simulated difficult airway. Ann Emerg Med 50:676-685. https://doi.org/10.1016/j.annemergmed.2007. 05.022

14. Lai HY (2020) Aerosol box. https://sites.google. com/view/aerosolbox/home. Accessed 4 Sept 2020

15. Lynch JB, Davitkov P, Anderson DJ et al (2020) Infectious diseases society of America guidelines on infection prevention for health care personne caring for patients with suspected or known COVID-19. Clin Infect Dis. https://doi.org/10.1093/ cid/ciaa1063
16. Maniar A, Jagannathan B (2020) The aerosol box. J Anaesthesiol Clin Pharmacol 36:S141-S143. https://doi.org/10.4103/joacp.JOACP 28320

17. Martin LD, Mhyre JM, Shanks AM et al (2011) 3,423 emergency tracheal Intubations at a university hospitalairway outcomes and complications. Anesthesiology 114:42-48. https://doi.org/10. 1097/ALN.0b013e318201c415

18. Maruyama K, Tsukamoto S, Ohno S et al (2010) Effect of cardiopulmonary resuscitation on intubation using a Macintosh laryngoscope, the AirWay Scope, and the gum elastic bougie: a manikin study. Resuscitation 81:1014-1018. https://doi.org/10.1016/j.resuscitation.2010.03. 041

19. Mascha EJ, Schober P, Schefold JC et al (2020) Staffing with disease-based epidemiologic indices may reduce shortage of intensive care unit staff during the COVID-19 pandemic. Anesth Analg 131:24-30. https://doi.org/10.1213/ANE. 0000000000004849

20. Matava CT, Yu J, Denning S (2020) Clear plastic drapes may be effective at limiting aerosolization and droplet spray during extubation: implications for COVID-19. Can J Anaesth 67:902-904. https:// doi.org/10.1007/s12630-020-01649-w

21. Nolan JP, Kelly FE (2011) Airway challenges in critical care. Anaesthesia 66:81-92. https://doi. org/10.1111/j.1365-2044.2011.06937.x

22. Okada Y, Nakayama Y, Hashimoto K et al (2020) Ramped versus sniffing position for tracheal intubation: a systematic review and meta-analysis. Am J Emerg Med. https://doi.org/10.1016/j.ajem. 2020.03.058

23. Sanfilippo F, Tigano S, Palumbo GJ et al (2020) Systematic review of simulated airway management whilst wearing personal protective equipment. $\mathrm{Br}$ J Anaesth 125:e301-e305. https://doi.org/10.1016/ j.bja.2020.06.011

24. Semler MW, Janz DR, Russell DW et al (2017) A multicenter, randomized trial of ramped position vs sniffing position during endotracheal Intubation of critically ill adults. Chest 152:712-722. https:// doi.org/10.1016/j.chest.2017.03.061

25. Sorbello M, El-Boghdadly K, Schumacher J, Ahmad I (2020) Personal protective equipment, airway management, and systematic reviews. Comment on Br J Anaesth 2020; 125: e301-5. Br J Anaesth 125:e360-e361. https://doi.org/10.1016/ j.bja.2020.06.038

26. Sorbello M, Rosenblatt W, Hofmeyr R et al (2020) Aerosol boxes and barrier enclosures for airway management in COVID-19 patients: a scoping review and narrative synthesis. $\mathrm{Br} J$ Anaesth 125:880. https://doi.org/10.1016/j.bja.2020.08. 038

27. Novel Coronavirus Pneumonia Emergency Response Epidemiology Team (2020) The epidemiological characteristics of an outbreak of 2019 novel Coronavirus diseases (COVID-19)—China, 2020. Zhonghua Liu Xing Bing Xue Za Zhi 2:113-122. https://doi.org/10.46234/ccdcw2020.032

28. Tran K, Cimon K, Severn M et al (2012) Aerosol generating procedures and risk of transmission of acute respiratory infections to healthcare workers: a systematic review. PLoS One. https://doi.org/10. 1371/journal.pone.0035797

29. Turner JS, Ellender TJ, Okonkwo ER et al (2017) Feasibility of upright patient positioning and intubation success rates at two academic EDs. Am J Emerg Med 35:986-992. https://doi.org/10.1016/ j.ajem.2017.02.011

30. Wang D, Hu B, Hu C et al (2020) Clinical characteristics of 138 hospitalized patients with 


\section{Originalien}

2019 novel Coronavirus-infected pneumonia in Wuhan, China. JAMA 323:1061. https://doi.org/10. 1001/jama.2020.1585

31. Wang W, Xu Y, Gao R et al (2020) Detection of SARS-coV-2 in different types of clinical specimens. JAMA 323:1843-1844. https://doi.org/10.1001/ jama.2020.3786

32. Weingart SD, Levitan RM (2012) Preoxygenation and prevention of desaturation during emergency airway management. Ann Emerg Med 59:165-175.e1. https://doi.org/10.1016/j. annemergmed.2011.10.002

33. Wu Z, McGoogan JM (2020) Characteristics of and important lessons from the coronavirus disease 2019 (COVID-19) outbreak in China: summary of a report of 72314 cases from the Chinese center for disease control and prevention. JAMA 323:1239-1242. https://doi.org/10.1001/jama. 2020.2648 